\title{
How Much of a Historic Town Can Be Mapped by a Terrestrial Laser Scanner within a Working Day? A Single Touch Workflow
}

\author{
CHRISTOPH FURST, NIKOLAUS STUDNICKA, MARTIN PFENNIGBAUER \\ RIEGL Laser Measurement Systems, Austria
}

\begin{abstract}
Downtown Vienna, with its world-famous cultural sites and architectural features, is most definitely worth preserving. One way to archive at least a digital 3D imprint is by means of laser scanning. While urban mapping with airborne or mobile laser scanning is fast and efficient, the resulting point clouds might not have the required resolution or might have gaps due to shadowing. Terrestrial laser scanning has the potential to overcome these limitations. However, it has long been considered time-consuming and laborintensive both during data capture and during the phase of data processing.

In order to challenge this common conception, we performed a field test with the new RIEGL VZ-400i terrestrial laser scanner. For eight hours, during the night of June 2nd to 3rd 2016, one single operator employed the instrument throughout the city center of Vienna. He managed to take 514 high-resolution laser scans with approximately $9 \mathrm{~m}$ between the scan positions.

The data acquired in the course of this test impressively demonstrates the potential of state-of-the-art terrestrial laser scanning to preserve detailed 3D-information of urban environments within a limited amount of time. This paper describes the complete workflow from the one touch operation in the field to the automatic registration process of the collected laser scans.
\end{abstract}

\section{Key words:}

Terrestrial Laser Scanning, High-Speed Mapping, Historic Urban Area.

SDH Reference:

Christoph Furst, Nikolaus Studnicka, Martin Pfennigbauer. 2017. How Much of a Historic Town Can

Be Mapped by a Terrestrial Laser Scanner within a Working Day? A Single Touch Workflow. SDH, $1,2,239-250$.

DOI : $10.14434 /$ sdh.v1i2.23332

\section{MOTIVATION}

The goal of this project was to gauge the capabilities of the RIEGL VZ-400i (Figure 1, left), which is one of the latest high performance terrestrial 3D laser scanners on the market. To prove its abilities for speed, precision and reliability, the following test scenario was chosen: a single operator would carry out as many scans as possible in a normal working day. A tripod was chosen as a support for the

Author's address: Christoph Fürst, Nikolaus Studnicka, Martin Pfennigbauer RIEGL Laser Measurement Systems, Austria; email:( cfuerst, nstudnicka, mpfennigbauer)@riegl.com

Permission to make digital or hardcopies of part or all of this work is granted without fee according to the open access policy of SDH.

(C) 2017 SDH Open Access Journal 
scanner in order to provide a stable base, thus allowing the operator to take full advantage of the high accuracy of the scanner. The possibility of using a car in stop-and-go motion was dismissed for several reasons: the car was an unstable platform, which would have put the scanner at a higher altitude; the scan shadow at the bottom would have thus been increased; and special permissions would have been required in order to access the pedestrian areas. The route was laid out so that the first and last scanning points would overlap (Figure 1 middle, right).
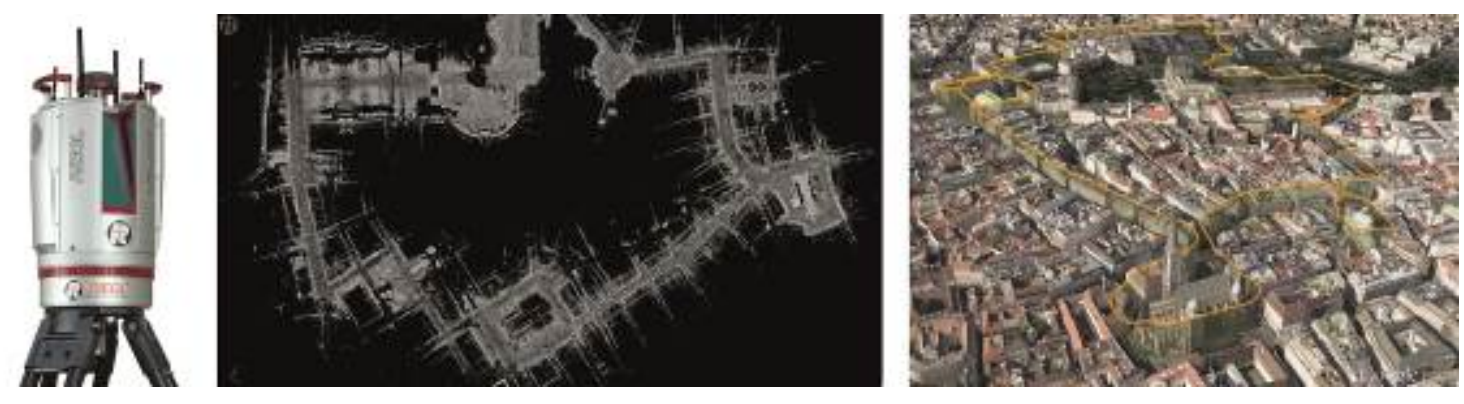

Figure 1. On the left: RIEGL VZ-400i Laser Scanner; in the middle: scan project of Vienna's city centre (orthogonal view from above). On the right: acquisition path visualized in Google Earth.

\section{ACQUISITION}

The first scan was taken at 11:45 pm on June 2, 2016 (Fig 2, left), on the east side of the Viennese opera, with additional scan positions at approximately every 9 meters, in order to provide detailed coverage of buildings and their features for future extractions [Kołakowska and Świerczyńska 2013]. As a standard pattern, a scan resolution of 0.05 degrees (Figure 3, left) across the whole field of view ("Panorama 50") was chosen.
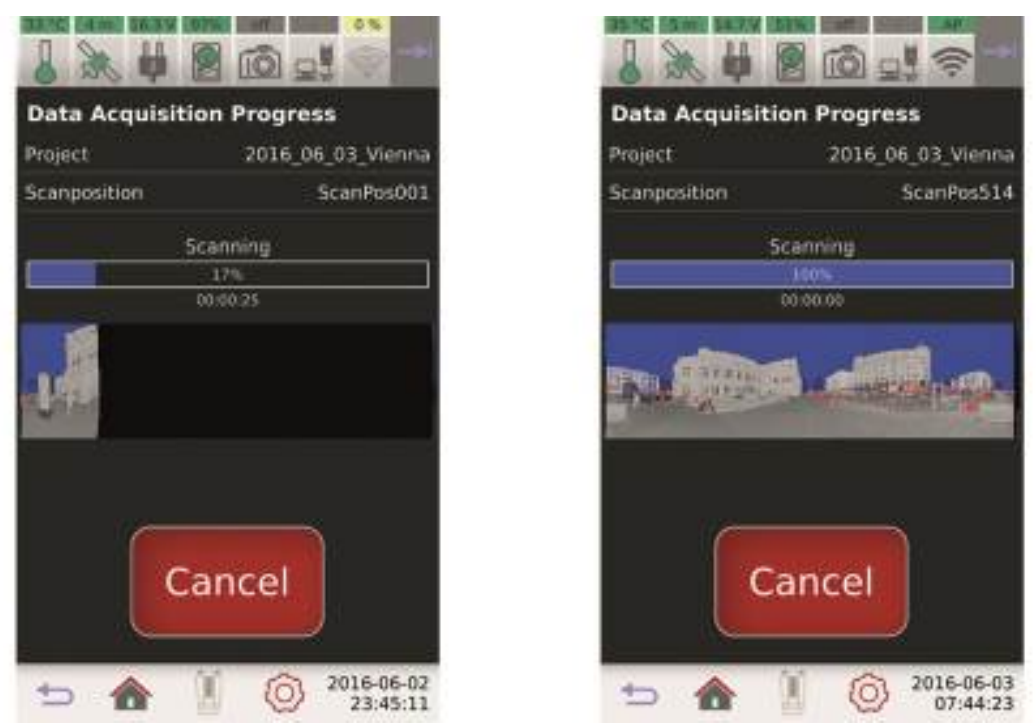

Figure 2. Example screenshots of the beginning and end of the scanning campaign. 
The scan settings were chosen to keep the required scan time short, lasting only for 30 seconds in a $360^{\circ} \mathrm{x} 100^{\circ}$ scan and producing an average of 14.4 million measurements per scan (Figure 4 , left). The use of panoramic scans (full field of view) in a chain-like order enables a rapid recording of position determination and offers large overlapping areas for the subsequent registration. Most of the scan shadows on facades and road surfaces were eliminated, owing to frequent rearrangements of the tripod, providing rich, dense data for later extraction of models [Ullrich et al. 2003]. Point spacing of the laser shots at 20 meters distance was around $17.5 \mathrm{~mm}$. In this project, 514 single scans were conducted during 8 hours of working time.
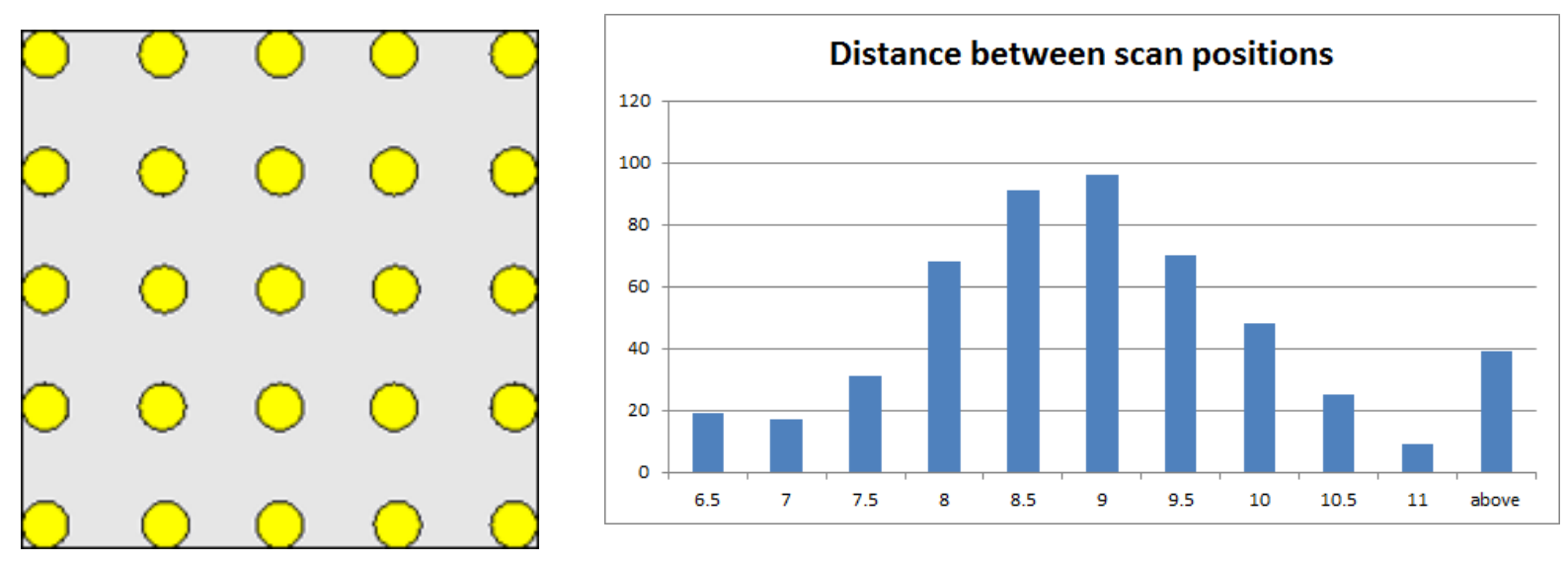

Figure 3. On the left: Scan pattern: 0.035 radiant beam divergence (yellow laser shot) compared to 0.05 degrees resolution (angular step width between the laser shots). On the right: average walking distance of 9 meters between two consecutive scan positions, represented in a diagram.
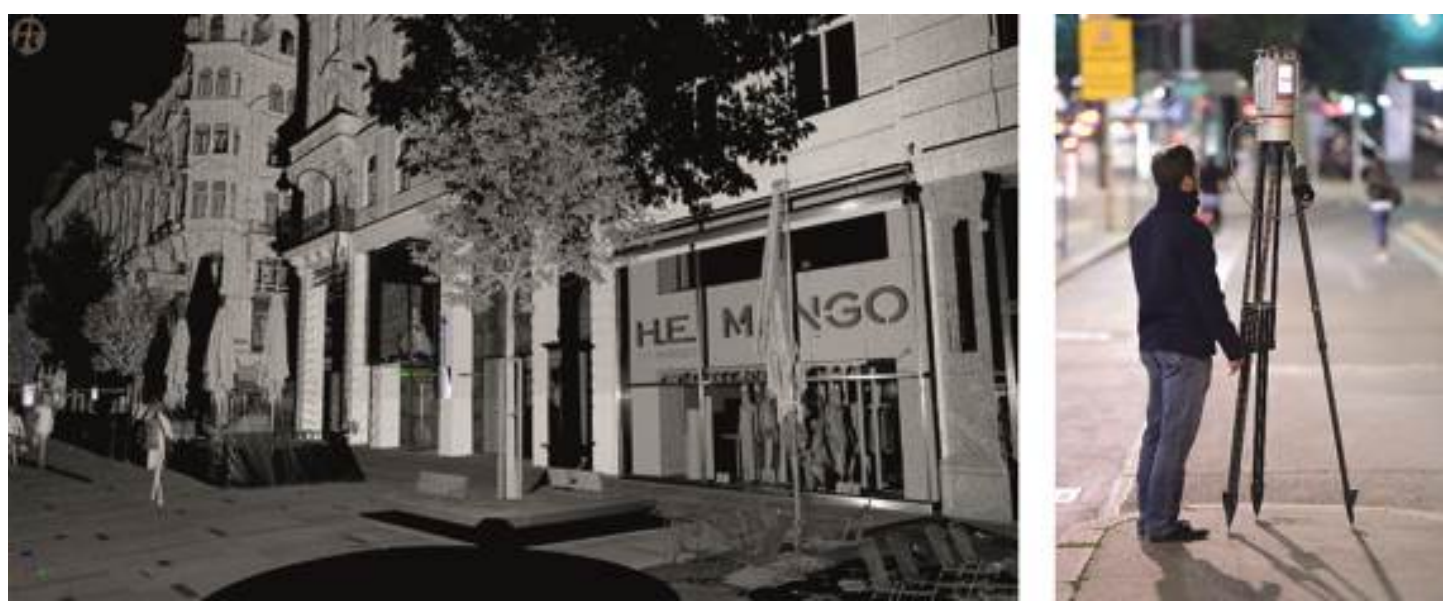

Figure 4. On the left: single scan ("Panorama 50"); the grey scale value represents the "reflectance". On the right: single operator with the RIEGL VZ-400i laser scanner. 
A total distance of 4.5 kilometers was covered, starting at the Viennese Opera, around the St. Stephen's Cathedral, St. Peter's Church, via Michaelerplatz to Ballhausplatz, Heldenplatz to Museumsquartier, and from Schillerplatz back to the east side of the Opera to acquire the last scan at 07:45 am. For every scan position, a so-called "single touch" of the Scan-Icon on the screen was sufficient. The built-in orientation sensors (MEMS) not only measured their own positions together with the internal GNSS sensors, but also automatically recognized the rearrangement of the tripod and automatically incremented the scan position. Nighttime surveying was selected because of the reduced number of people and less traffic on the road. Owing to the lighting situation at night, the conventional method of additionally acquiring calibrated photos with a calibrated digital camera was dispensed with. The measuring tripod, made out of carbon and the commercially available LiPo batteries (Figure 4, right) were chosen for their light weight.

Additionally, to improve and check the absolute accuracy of the project, in co-operation with EKG Baukultur $\mathrm{GmbH}$, control points were acquired using a Trimble R8 GNSS Receiver (Figure 5).


Figure 5. On the left: Data of scan position 236 including indicated control point. On the right: measuring of the control point of the same position using a Trimble R8 GNSS receiver.

\section{AUTOMATIC REGISTRATION OF THE SCANS THROUGH RISOLVE}

The scans were processed using the RIEGL software RiSOLVE (Figure 6). At the beginning, the compressed scan data from the laser scanner were converted into Octree-organized point clouds, which consequently made possible a quick visualization of a large amount of data. The desired 
coordinate system should already be known before importing the data in order to set a correct configuration of GeoSysManager (Figure 9). This allows for an automatic transformation of the measured coordinates from the GNSS-receiver's coordinates (WGS84) to the coordinate system demanded by the customer (e.g. Gauss-Krueger).

Characteristic of RiSOLVE is the automatic and precise registration of single scans to each other. This is carried out in three steps:

1) rough registration using data of the built-in sensors (GNSS, MEMS)

2) automatic improvement through image-matching algorithms

3) optional: applying links between control points and scans

4) improvement with RIEGL's automatic "Multi-Station-Adjustment" process, resulting in a precision of typically a few millimeters [Dold and Brenner 2006].

The final dataset can be exported into handy pdf-plots or as a registered point cloud for further processing in third party software.

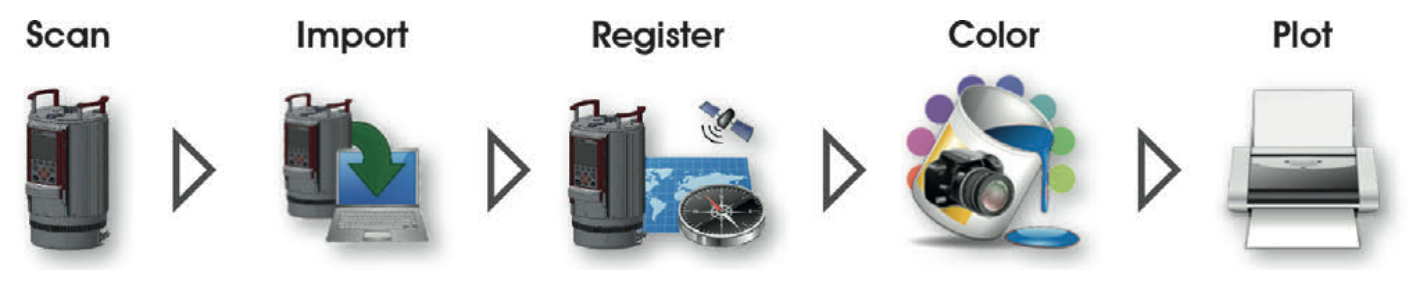

Figure 6. Schematic workflow of RiSOLVE (colorization was not applied in this project).

Being a field test of previously unknown magnitude, the processing steps displayed in Table I were carried out and tested several times in order to optimize performance and processing time.

Table I: Processing Time of Each Working Phase Step

\begin{tabular}{|l|l|l|}
\hline \multicolumn{1}{|c|}{ Action } & \multicolumn{1}{|c|}{ Time for 514 scan positions } \\
\hline Copying from scanner to external hard drive & Automatic & 20 minutes \\
\hline $\begin{array}{l}\text { Converting single scans within RiSOLVE } \\
\text { (with multiple-time-around processing) }\end{array}$ & Automatic & 3 hours \\
\hline Registering scans within RiSOLVE & Automatic & 6 hours \\
\hline Combining control points with scans & Manual & 2 hours \\
\hline Bundling adjustment using "Multi-Station-Adjustment" & Automatic & 23 hours \\
\hline $\begin{array}{l}\text { Creating reduced single point cloud from } 514 \text { scans }(10 \mathrm{~cm} \text { or } 47 \\
\text { million points) }\end{array}$ & Automatic & ca. 80 minutes \\
\hline $\begin{array}{l}\text { Exporting of reduced point cloud in Gauss Krueger coordinate } \\
\text { system into the Bentley Microstation format (*.pod) }\end{array}$ & Automatic & $\begin{array}{l}\text { 2" (depends on the point } \\
\text { cloud's resolution) }\end{array}$ \\
\hline
\end{tabular}


1:244 C. Fürst, et al.

\section{EVALUATION OF RESULTING POINT CLOUD DATA}

To evaluate the quality of the relative registration, a random selection of a number of measured points on a planar surface was taken (Figure 7, top left). Within that selection, RiSOLVE calculated the standard deviation of these points with regard to a plane that best fits the point cloud. For a single scan the standard deviation was given at $2.8 \mathrm{~mm}$; for eight overlapping scans it was $3.8 \mathrm{~mm}$ (Figure 7 , top right), indicating that the automatic registration led to a highly accurate result.


Figure 7. Check of the accuracy of the registration process. Top left: Selection of the checked façade. Top right: information of 8 scans at ca. $3.8 \mathrm{~mm}$ standard deviation; below: overlapping point cloud-each scan colored differently. 
The evaluation of the absolute accuracy was done by including the control points and the linked tie points from the data in RIEGL's "Multi Station Adjustment". As highlighted in Figure 8, the absolute accuracy of the data was $2.4 \mathrm{~cm}$ with 26 control points being used.

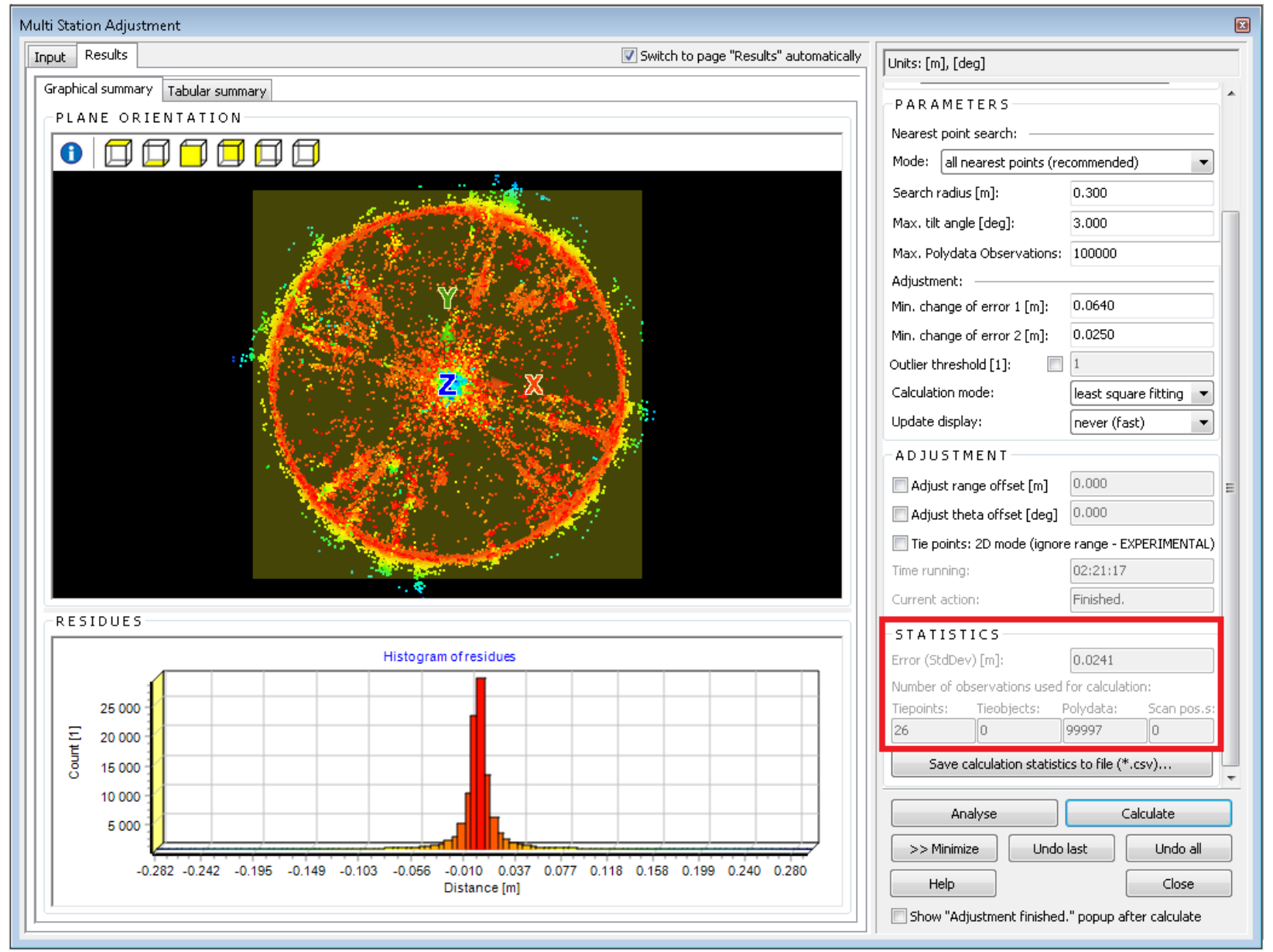

Figure 8. Result page of Multi Station Adjustment with histogram of residues (left) and final statistics (right, highlighted).

Though the number of objects crossing the scans was already quite low due to the time when the project took place, some can still be found in the scans. In order to remove these objects (e.g., pedestrians, cars, trams, etc.) RiSOLVE also offers a semi-automatic filter that can be adapted to the user's individual requirements (Figure 9).

For further use, the point cloud with a reduced number of points (47 million compared to the originally around 7 billion single scan points) was visualized in Bentley's Microstation together with the "Wiener Mehrzweckkarte" (Figure 10, right), a multifunctional map of Vienna, for comparison and quality improvement of this map. Additionally, a plot covering the entire covered area was created as an 8 Giga pixel bmp, in order to have an easily accessible overview of the project that still shows its details and point density (Figure 11). 

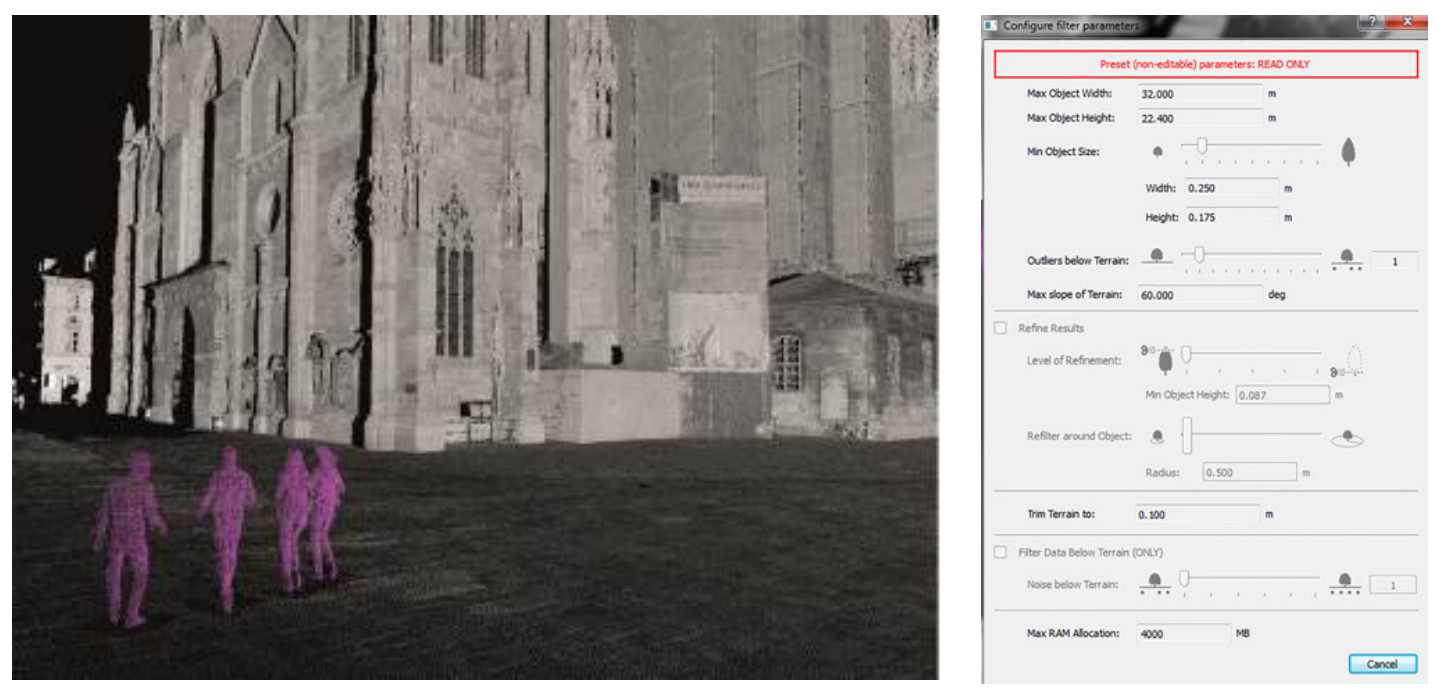

Figure 9. On the left: semiautomatic filter for human beings. On the right: settings for this filter.
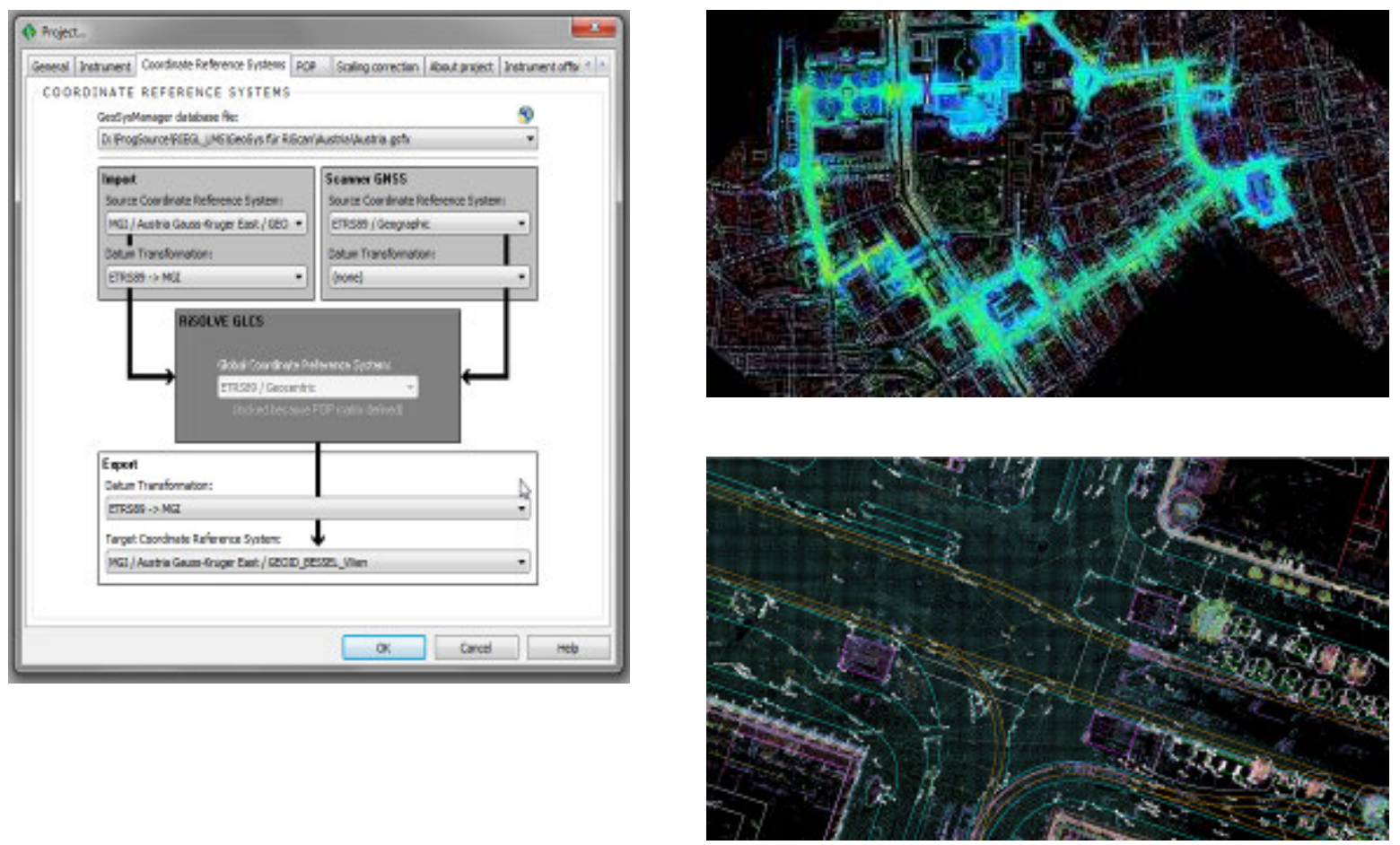

Figure 10. On the left: GeoSysManager used for transformation of coordinate systems in RiSOLVE. On the right: visualization of the reduced point cloud together with the "Wiener Mehrzweckkarte" in Bentley's Microstation. 

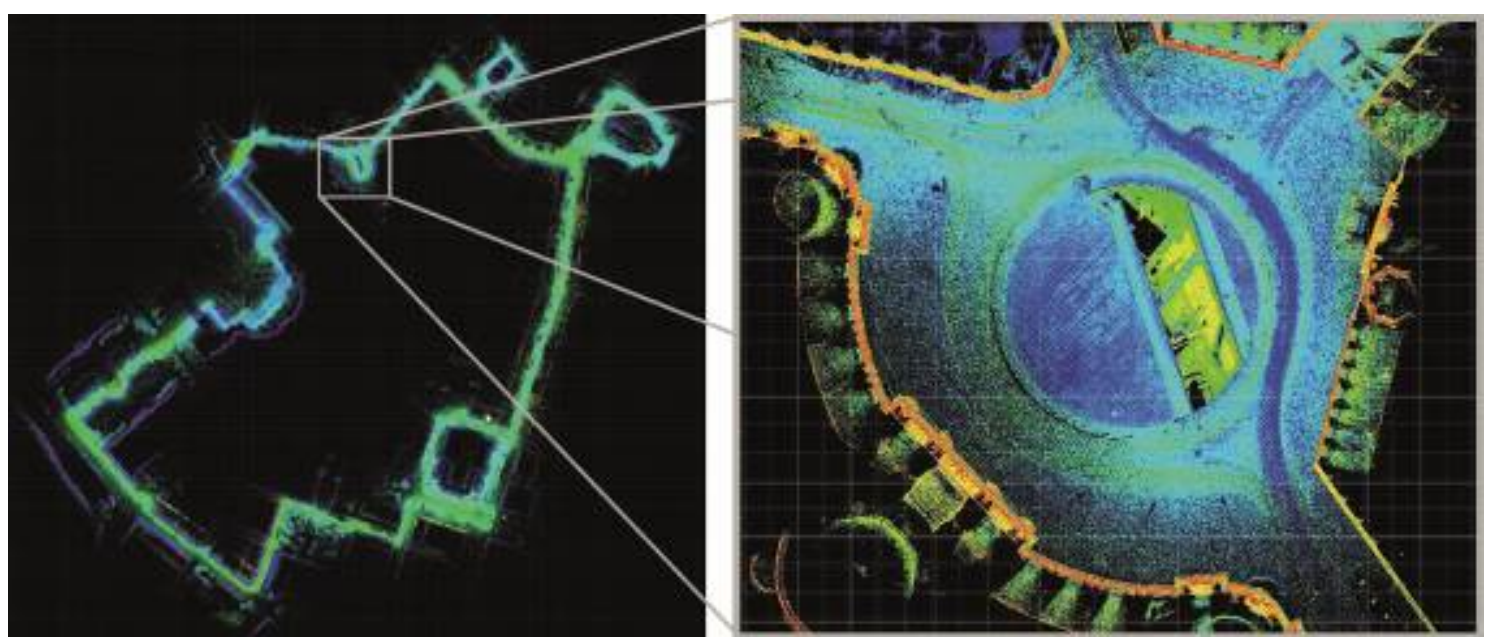

Figure 11. On the left: the whole project depicted in a bmp with 8 Giga pixels. On the right: orthogonal detail projection of the Michaelerplatz (scale: 1:250).

Additionally, part of the acquired data was used in order to create a highly detailed 3D Model of the fountain at Michaelerplatz (Figure 12).
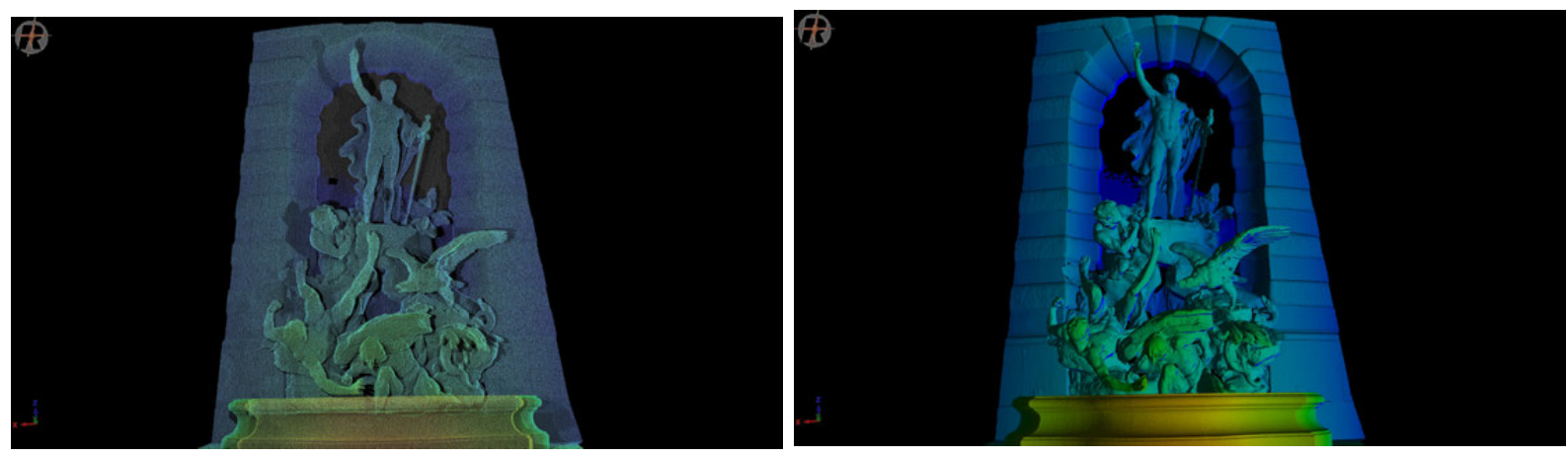

Figure 12: On the left: point cloud of the fountain "Die Macht zu Lande". On the right: mesh of the fountain.

\section{CONCLUSION}

This project showcases the potential of acquisition done with a high speed terrestrial laser scanner on a tripod. This may become crucial in order to preserve the cultural heritage of areas endangered by war where quick operation is essential and operation on cars might not be possible because roads are blocked by rubble.

This suggests that terrestrial laser scanning, which has already proven useful and efficient in acquisition of single sites [Hejbudzka and Dumalski 2013], will possibly become a more frequently used tool for large-area cultural heritage preservation, as it is easy to apply and lower in cost than mobile systems. 
Combining this with the automatic Registration of RiSOLVE, the following results have been achieved:

- The unprecedented acquisition of 514 high resolution scans in only eight hours with a single instrument by a single operator. This was possible due to the high vertical scan speed resulting in 240 scan lines/second in order to optimally utilize the high pulse repetition rate of $1.2 \mathrm{MHz}$ while still creating an even pattern.

- Only one operator was necessary, who apart from rearranging the tripod only needed to execute a single touch on the screen per position. An assistant provided spare batteries for the scanner and nutrition for the operator.

- Automatic registration of all scans.

- Automatic transformation of measured points from WGS84 into the Gauss Krueger coordinate system through GeoSysManager within the RiSOLVE software.

Table II shows the final parameters reached in the project.

Table II: Final parameters of the project

\begin{tabular}{|r|l|}
\hline Length of acquisition path & ca. $4.5 \mathrm{~km}$ \\
\hline Total number of measurements & 7 billion \\
\hline Average points per position & 14.4 million \\
\hline Average time per position & 56 seconds (including rearrangement) \\
\hline Standard deviation single scan (nr ...): & $2.8 \mathrm{~mm}$ \\
\hline Standard deviation of 8 scans on a selected plane (nr 85-92) & $3.8 \mathrm{~mm}$ \\
\hline Average processing time per position & ca. 4 minutes \\
\hline
\end{tabular}

\section{DISCUSSION OF OUTCOMES}

This project for the first time proves that the VZ-400i laser scanner is capable of recording this many roads and facades in such a short period of time. Now the question arises if, in the future, complete districts of cities can be recorded in this way.

The following possible improvements are proposed by the authors:

Hardware:

Instead of the built-in GNSS system, one could install an external GNSS receiver on the RIEGL VZ400i Scanner (Figure 12). Via Bluetooth or serial connection, the positioning data, accurate to $1 \mathrm{~cm}$, would already be bundled in the recording. The use of control points could therefore be possibly avoided. 


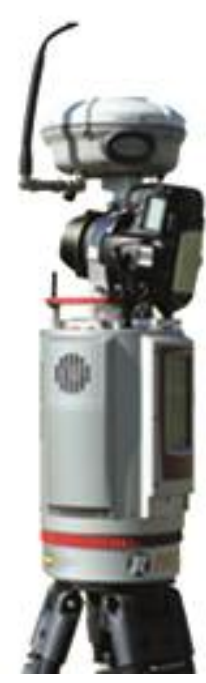

Figure 12. RIEGL VZ-400i with Nikon D810 and Trimble R8 GNSS-Receiver with RTK antenna.

Alternative new workflow (Figure 13):

Through accurately measured control points, panorama scans of main street crossings would be clearly registered. The relatively short stretches of roads between these crossings could be processed in single RiSOLVE projects. Project sizes would be minimized and large areas in the urban surroundings could still be measured terrestrially.

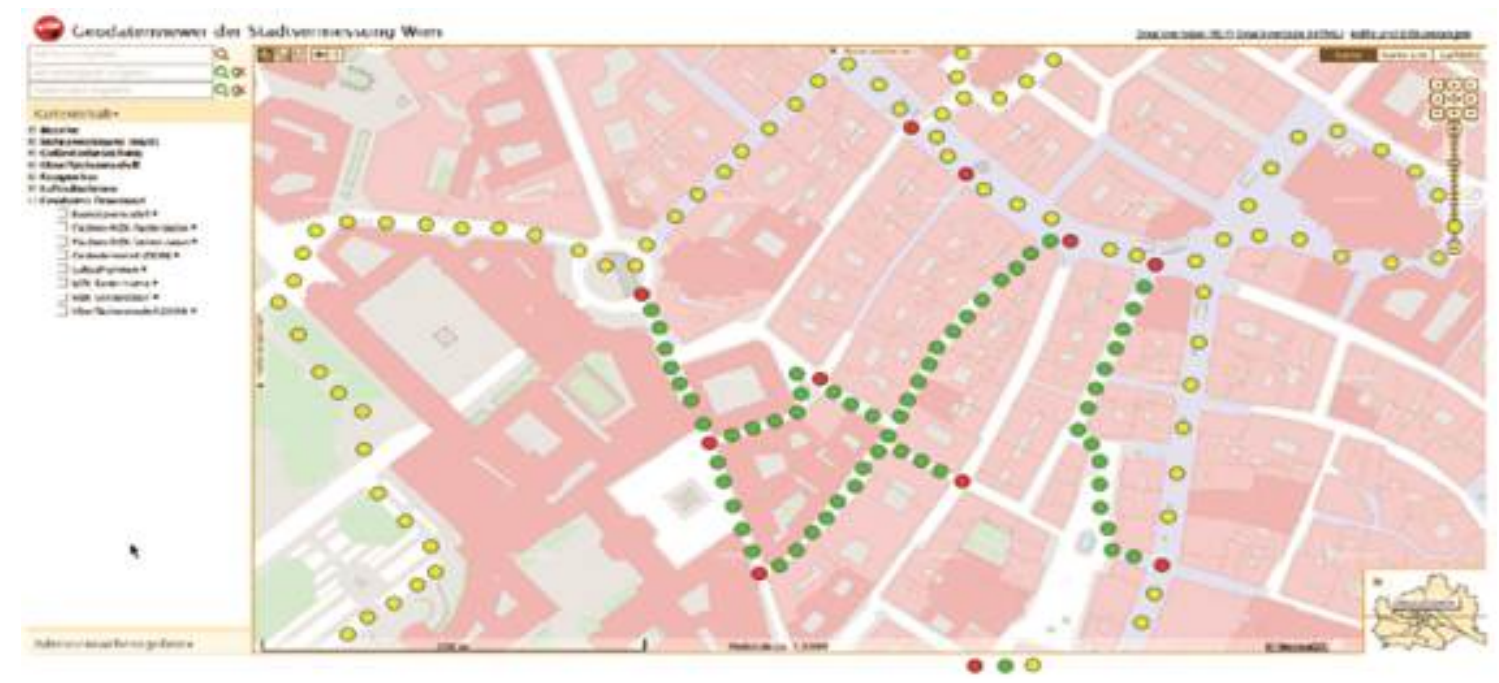

Figure 13. Schematic of new Workflow. Red points: registered cross-way scans. Green points: connecting scans between cross-ways (registered in RISOLVE). 
Table III provides a quick overview of the characteristics of different types of laser scanning that could be applied for a similar acquisition.

Table III: Comparison between different laser scanning methods: TLS (terrestrial laser scanning), MLS (mobile laser scanning), ALS (airborne laser scanning)

\begin{tabular}{|c|c|c|}
\hline Terrestrial Laser Scanning & Mobile Laser Scanning & Airborne Laser Scanning \\
\hline \multicolumn{2}{|c|}{ Scanning of streets/facades } & House tops/streets \\
\hline \multicolumn{2}{|c|}{ Control points required } & Few control points required \\
\hline \multicolumn{2}{|c|}{ High resolution } & Medium resolution \\
\hline Static & \multicolumn{2}{|c|}{ Cinematic } \\
\hline Moderate speed & High speed & Very high speed \\
\hline Quick availability & $\begin{array}{l}\text { Need for driving permission } \\
\text { (Pedestrian zone) }\end{array}$ & Need for flying permission \\
\hline
\end{tabular}

\section{REFERENCES}

Christoph Dold and Claus Brenner. 2006. Registration of terrestrial laser scanning data using planar patches and image data. ISPRS Commission V Symposium "Image Engineering and Vision Metrology". IAPRS Volume XXXVI, Part 5, Dresden September 2006.

Karolina Hejbudzka and Andrzej Dumalski. 2013. Digital heritage documentation using terrestrial laser scanning technology. In R. Źróbek \& D. Kereković, eds. GIS and its Implementation. Zagreb: Croatian Information Technology Society - GIS Forum, , 46-56.

Maria Kołakowska and Ewa Świerczyńska. Selected aspects of using terrestrial laser scanning technology as the source of additional data for building information modeling. Department of Geodesy and Cartography 2014. Vol. 4,4 (2013). http://journal.young-scientists.eu Warsaw University of Technology. Warsaw.

Andreas Ullrich et al. 2003. 3D-Laser-Sensors and their Applications in Archaeology and Modeling of Historic Buildings. Vienna.

http://whc.unesco.org/en/danger/

Received March 2017; revised July 2017; accepted August 2017. 